\title{
Clouston hidrotic ectodermal dysplasia (HED): genetic homogeneity, presence of a founder effect in the French Canadian population and fine genetic mapping
}

Zoha Kibar ${ }^{1,2}$, Marie-Pierre Dubé ${ }^{1,2}$, Julie Powell ${ }^{3}$, Catherine McCuaïg ${ }^{3}$, Susan J Hayflick ${ }^{4}$, Jonathan Zonana ${ }^{4}$, Alain Hovnanian ${ }^{5}$, Uppala Radhakrishna ${ }^{6}$, Stylianos E Antonarakis ${ }^{6}$, Antranik Benohanian? ${ }^{7}$, Amy D Sheeran ${ }^{8}$, Mark L Stephan ${ }^{9}$, Richard Gosselin ${ }^{10}$, David P Kelsell ${ }^{11}$, Arnold L Christianson ${ }^{12}$, F Clarke Fraser ${ }^{2,13}$, Vazken M Der Kaloustian ${ }^{2,13}$ and Guy A Rouleau ${ }^{1,2}$

${ }^{1}$ Centre for Research in Neurosciences, Montreal General Hospital Research Institute; ${ }^{2}$ M cGill University, M ontréal; ${ }^{3}$ Départment de Dermatologie, Hôpital Sainte Justine and Université de M ontréal, Québec, Canada; ${ }^{4}$ Department of Molecular and Medical Genetics, Oregon Health Sciences University, Portland, OR, USA; ${ }^{5}$ The Wellcome Trust Centre for Human Genetics, University of Oxford, UK; ${ }^{6}$ Division of Medical Genetics, University of Geneva, Medical School and University Hospital, Switzerland; ' ${ }^{7}$ Service de Dermatologie, Centre Hospitalier de I'Université de M ontréal, Québec, Canada; ${ }^{8}$ D epartment of M edical and M olecular Genetics, Indiana University, Indianapolis; ${ }^{9}$ Developmental Pediatrics and Dysmorphology, Madigan Army Medical Center, Tacoma, Washington, USA; ${ }^{10}$ Centre Hospitalier de I'Université de Sherbrook, Canada; ${ }^{11}$ Centre for Cutaneous Research, St Bartholomew's and the Royal London Hospital, London, UK; ${ }^{12}$ Department of Human Genetics and Developmental Biology, Faculty of Medicine, University of Pretoria, South Africa; ${ }^{13} \mathrm{~F}$ Clarke Fraser Clinical Genetics Unit, Division of Medical Genetics, M ontreal Children's Hospital, M ontréal, Québec, Canada

HED is an autosomal dominant skin disorder that is particularly common in the French Canadian population of south-west Quebec. We previously mapped the HED gene to the pericentromeric region of chromosome 13q using linkage analysis in eight French Canadian families. In this study, we extend our genetic analysis to include a multiethnic group of 29 families with 10 polymorphic markers spanning $5.1 \mathrm{cM}$ in the candidate region. Two-point linkage analysis strongly suggests absence of genetic heterogeneity in HED in four families of French, Spanish, African and Malaysian origins. Multipoint linkage analysis in all 29 families generated a peak lod score of 53.5 at D13S1835 with a 1 lod unit support interval spanning $1.8 \mathrm{cM}$. Recombination mapping placed the HED gene in a $2.4 \mathrm{cM}$ region flanked by D13S1828 proximally and D13S1830 distally. We next show evidence for a strong founder effect in families of French Canadian origin thereby representing the first example of a founder disease in the south-west part of the province of Quebec. Significant association was found between HED in these families and all markers analysed (Fisher's exact test, $P<\mathbf{0 . 0 0 1}$ ). Complete allelic association was detected at D13S1828, D13S1827, $D 1351835, D 135141$ and $D 135175\left(P_{\text {excess }}=1\right)$ spanning $1.3 \mathrm{cM}$. A major haplotype including all 10 associated alleles was present on $65 \%$ of affected chromosomes. This haplotype most likely represents the founder haplotype that introduced the HED mutation into the French Canadian population. Luria-Delbrück equations and multipoint likelihood linkage disequilibrium analysis positioned the gene at the D13S1828 locus (likely range estimate: $1.75 \mathrm{cM}$ ) and $0.58 \mathrm{cM}$ telomeric to this marker (support interval: 3.27 cM) respectively. European Journal of Human Genetics (2000) 8, 372-380.

Correspondence: Dr Guy A Rouleau, Center for Research in

Neurosciences, Room L7-224, Montreal General Hospital Research

Institute, 1650 Cedar Avenue, Montréal, Québec, H3G 1A4, Canada.

Tel: +15149376011 ext. 4235; Fax: +15149358265;

E-mail: mi32@musica.mcgill.ca

Received 16 September 1999; revised 7 January 2000; accepted

13 January 2000 
Keywords: hidrotic ectodermal dysplasia; genetic homogeneity; genetic mapping; linkage disequilibrium analysis; founder effect; French Canadian population

\section{Introduction}

Clouston hidrotic ectodermal dysplasia (HED) is a rare form of genodermatosis transmitted as an autosomal dominant condition with complete penetrance and variable expressivity. ${ }^{1}$ Though HED has been described in families of various ethnic origins, ${ }^{2-6}$ it is particularly common in families of French Canadian origin suggesting a founder effect for the HED mutation in this population. ${ }^{7-9}$ Interestingly, HED occurs predominantly in south-west Quebec, a region quite distinct from the north-east part of the province where all previous founder effects have been found. The main features of HED are nail deformities frequently associated with paronychial infections, hair defects that range from brittleness and slow growth rate to partial or total alopecia, and thickening of the skin of the palms and soles that occurs in varying degrees of severity. ${ }^{10}$

Using linkage analysis in eight French Canadian families segregating HED, the HED gene was mapped to the pericentromeric region of chromosome13q with a two-point lod score of 8.12 at zero recombination from the marker D13S175. Haplotype analysis in this study placed the HED gene in a region spanning at least $15 \mathrm{cM}$ between the centromere and the marker D13S143. ${ }^{9}$ Later studies have confirmed linkage of HED to this region in an ethnically diverse group of families (Indian, French and Scottish-Irish), demonstrating absence of genetic heterogeneity in HED. ${ }^{5,6}$

As a step towards the identification of the HED gene, a radiation hybrid map of 48 loci on chromosome13q including the HED locus was constructed and eight new polymorphic markers were isolated in the candidate region. ${ }^{11}$ In the current study, we genotype an extended panel of $29 \mathrm{HED}$ families of various ethnic origins with a set of 10 polymorphic markers to study genetic homogeneity in HED and finely map the HED gene. In addition, we present evidence for a founder effect for this disease in the French Canadian population and use linkage disequilibrium mapping to further refine the HED-containing interval.

\section{Subjects, materials and methods HED families}

Twenty-nine families segregating HED were available for this study: 23 French Canadian, one Indian, one Scottish-Irish, one French, one Spanish, one South African and one Malaysian. They include 172 affected among a total of 287 subjects. The Indian, Scottish-Irish, and South African families have been previously described., ${ }^{5,12,13}$ The French family was collected by AH in the UK; two branches of this family have been reported by Giraud et al ${ }^{14}$ and Taylor et al. ${ }^{6}$ The Malaysian family was described by Stevens et al. ${ }^{15}$ The Spanish family was collected from the United States. Pedi- grees of the French, Spanish, African and Malaysian families are shown in Figure1. The French Canadian sample included eight families initially described, ${ }^{9}$ two families described by Taylor et al ${ }^{6}$ and 13 new families. All patients presented with various degrees of nail defects, hair abnormalities and palmoplantar hyperkeratosis. In addition, the African family had abnormal cardiac findings associated with HED.

\section{DNA and microsatellite analyses}

DNA extraction and genotyping were done as previously described. ${ }^{9}$ Ten (CA $)_{n}$ polymorphic markers were used to genotype the HED families. They include seven new markers we have recently isolated in the candidate region, D13S1826, D13S1828, D13S1827, D13S1835, D13S1830, D13S1831 and D13S1832 ${ }^{11}$ along with D13S175, D13S141 and D13S143. The order of these markers was obtained from the RH map we constructed in the region with 1000:1 level of significance. This order was examined by the CRI-M AP program developed by Phil Green ${ }^{16}$ using combined data from 14 CEPH reference families and $20 \mathrm{HED}$ families. The order of these markers and intermarker genetic distances in Kosambi CM are as follows: D13S1826-0.2 - D13S1828-0.5 - D13S1827-0 - D13S1835-0.8 - D13S141-0 - D13S175-1.1 - D13S1830-0 - D13S1831-0 D13S1832-2.5 - D13S143. The relative $\log _{10}$-likelihoods of $2.13,4.29,5.27,5.10$ and 7.92 were obtained with permutations of loci D13S1826 - D13S1828, D13S1828 - D13S1827, D13S1835 - D13S141, D13S175 - D13S1830 and D13S1832 D13S143, respectively. This order was compatible with data from haplotype analysis. For markers not separated by crossover events in our sample, a fixed intermarker genetic distance of $0.01 \mathrm{cM}$ was assumed for multipoint analysis.

\section{Linkage analysis}

Two-point linkage analysis was performed using the MLINK or ILINK programs of the LINKAGE5.1 package. ${ }^{17} \mathrm{Multi-}$ point analysis was done using the VITESSE program developed by $\mathrm{O}^{\prime}$ Connell and Weeks. ${ }^{18}$ The mode of inheritance was considered to be autosomal dominant with complete penetrance, with an estimated gene frequency of 0.0001 (French Canadian) and 0.00001 (non-French Canadian). Recombination fractions were assumed to be equal in females and males. Allele frequencies for all markers were obtained from the genotypes of 50CEPH control individuals.

\section{Linkage disequilibrium analysis}

French Canadian sample Four French Canadian familes are related four generations back and hence were considered as one family for linkage disequilibrium analysis. Consequently, only 20 French Canadian families were available for this analysis. One affected individual carrying the full disease 

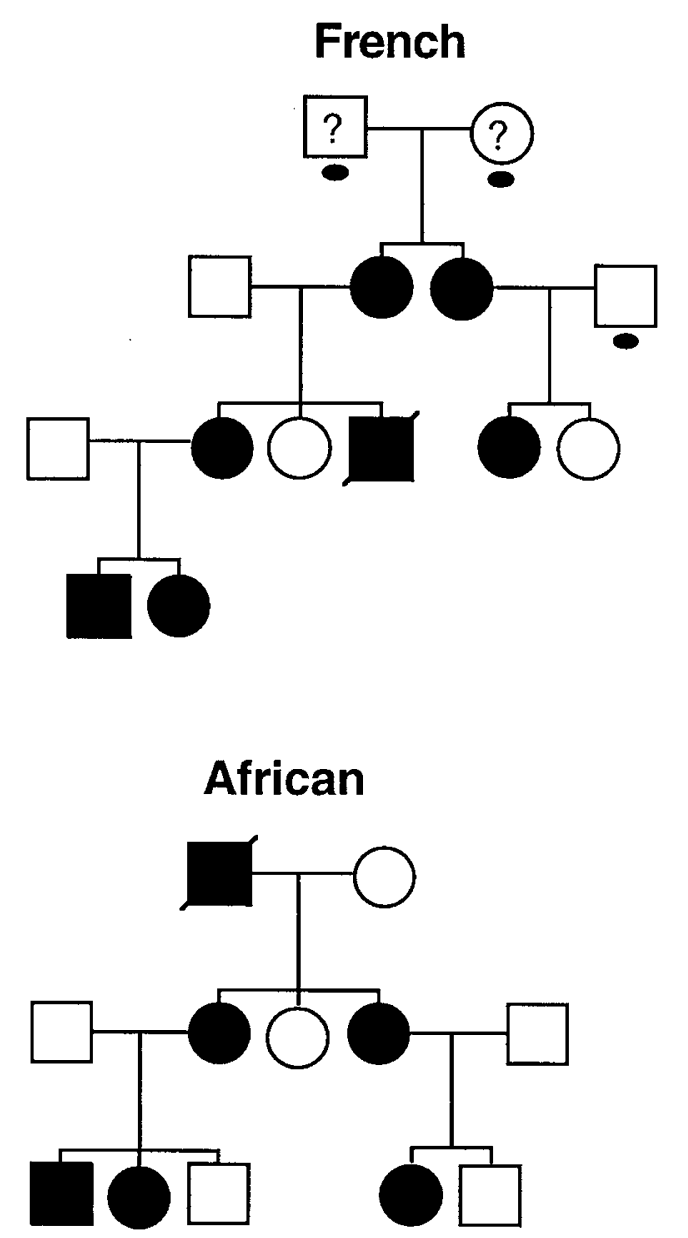

\section{Spanish}

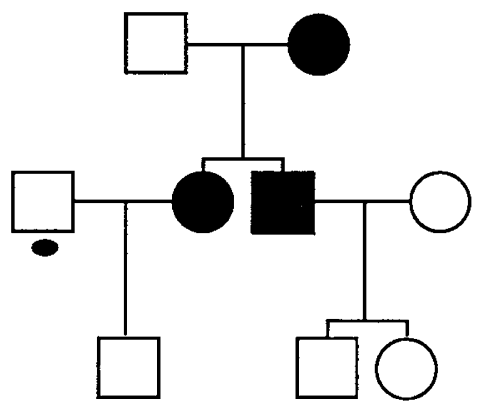

Malaysian

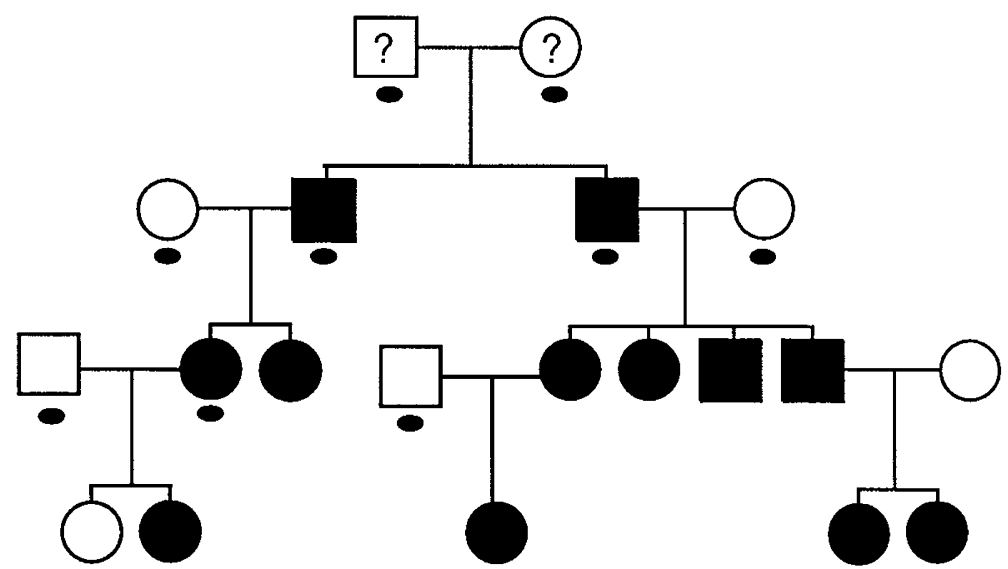

Figure 1 Pedigrees of the French, Spanish, African and Malaysian families used in this study. All live members have DNA available for analysis except those marked by black ovals.

haplotype from each of these families was selected for analysis, except in those families where a recombination event took place, then two or more affected hapl otypes were included accordingly. This gave rise to a total of 26 affected HED chromosomes. The normal population allele frequency was obtained from the genotypes of 29 unaffected spouses participating in this study.

Allelic association Non-random allelic association between the markers and the HED gene in the French Canadian affected chromosomes was studied as described el sewhere. ${ }^{19}$

Luria-Delbrück equations for LD mapping The Luria and Delbrück derived equations were used to generate an estimate of the recombination fraction $(\theta)$ between the ten markers taken separately and the HED gene. The expected recombination fraction and likely range were calculated according to the equations presented in Hästbacka et al. ${ }^{20}$ The HED chromosomes' population growth rate was estimated using the disease's prevalence in today's population. Based on clinical record collections covering the whole province, the number of disease chromosomes was estimated to be 300 . The number of generations since the introduction of the disease chromosome was estimated to be 8 , according to indications of a later introduction of the disease chromosome to the population as reported by Clouston, ${ }^{8}$ which is also supported by the low prevalence of the disorder in the population.

\section{Multipoint linkage disequilibrium analysis}

A multipoint linkage disequilibrium analysis was performed using the DISMULT version 2.1 routine of the likelihood method developed by JD Terwilliger. ${ }^{21}$ Ten markers were 
Table 1 Absence of genetic heterogeneity in HED

\begin{tabular}{|c|c|c|c|c|c|c|c|c|c|c|}
\hline \multirow[b]{2}{*}{ Family origin } & \multirow[b]{2}{*}{ S1826 } & \multirow[b]{2}{*}{ S1828 } & \multicolumn{7}{|c|}{ Lod score at recombination fraction $=0$ from marker } & \multirow[b]{2}{*}{ S143 } \\
\hline & & & S1827 & S1835 & S141 & S175 & S1830 & S1831 & S1832 & \\
\hline Indian & 7.97 & 6.94 & 5.63 & 0 & 1.57 & $1.28^{a}$ & 6.09 & 7.60 & 5.70 & 0.38 \\
\hline Scottish-Irish & 1.11 & 3.44 & 0 & 3.17 & 2.88 & 1.93 & 3.55 & 1.72 & 3.61 & 1.11 \\
\hline French & 1.78 & 1.79 & 1.79 & 1.80 & 1.02 & 0.75 & 0.24 & 0.19 & -infinity & -infinity \\
\hline Spanish & 1.20 & 1.20 & 0.90 & 0.44 & 1.20 & 0.90 & 0 & 0.90 & 0.60 & 1.20 \\
\hline South African & 2.11 & $0.91^{b}$ & -0.04 & 2.11 & -0.10 & 0.76 & -0.05 & 1.81 & 1.81 & -0.03 \\
\hline Malaysian & 2.04 & 2.67 & 2.81 & 2.93 & 0.38 & 1.38 & $0.10^{c}$ & 1.05 & 0.35 & 0.59 \\
\hline
\end{tabular}

Recombination fractions: ${ }^{\mathrm{a}} 0.035 \mathrm{~b}^{\mathrm{b}} 0.117,{ }^{\mathrm{c}} 0.111$.

analysed simultaneously according to the map order and distances mentioned above. The minimum and maximum values for the decay was set to be from 5 to 20. The number of test points for theta in the inter-marker intervals was set to 10 , and the allele frequency for the disease gene was set at 1 in 10000 according to the estimated number of cases observed in the population.

\section{Results \\ Two-point linkage analysis in the non-french canadian families}

Six families of various ethnic origins - Indian, Scottish-I rish, French, Spanish, South African and Malaysian - were tested for linkage of the HED gene to 10 pericentromeric chromosome13q markers. Linkage in the Indian and Scottish-Irish families to this region was previously demonstrated; ${ }^{5,6}$ this study extends the genotyping analysis of these families with seven new markers. Table 1 shows the maximum lod scores obtained with each marker. Most maximum lod scores were obtained at zero recombination from the markers analysed. Lod scores above 3.00 were obtained only with the Indian and Scottish-Irish families. However, the Malaysian family gave a maximum lod score very close to $3.00\left(Z_{\max }=2.93\right)$ with the marker D13S1835. The South African, Spanish and French families generated maximum lod scores of 2.11, 1.20 and 1.80 , respectively. Since these lod scores are equal to the maximum possible lod scores those families can generate assuming $100 \%$ informativity of markers, the HED gene in these families is most probably linked to the markers analysed. Lod scores $<-2.00$ were obtained only in the French family with the markers D13S1832 and D13S143, indicating the presence of a recombination event with the two markers. These results suggest absence of genetic heterogeneity in HED in the multiethnic group of families analysed.

\section{Multipoint linkage analysis}

A multipoint linkage analysis was carried out to use information in all 29HED families. Lod scores were calculated separately for the French Canadian and non French Canadian families with the corresponding estimated gene frequency and then added up. In each test run, we were able to analyse only four loci simultaneously. After covering the entire map, we repeated the analysis with the four most informative markers chosen from the runs that generated the highest lod scores. Multipoint linkage analysis using the genetic map: D13S1828-0.51cM-D13S1835-0.81 cMD13S175-1.1 CM-D13S1830 generated a maximum lod score of 53.5 at D13S1835. The one lod unit support interval spans $1.81 \mathrm{cM}, 0.1 \mathrm{cM}$ telomeric to D13S1828 and $0.51 \mathrm{cM}$ centromeric to D1351830. The 3lod unit support interval only extends $0.5 \mathrm{cM}$ distally (data not shown).

\section{Recombination mapping}

Haplotypes were constructed manually, assuming a minimum number of recombination events. Nine observed recombinants were detected in our families (data not shown), three of which have been previously described. Figure 2 shows the two most critical recombinations that would define the new boundaries for the HED candidate region: individualsII-5 in family A and II-4 in family B that would place the HED gene telomeric to D13S1828 and centromeric to D13S1830 respectively. The region flanked by these two markers spans $2.4 \mathrm{cM}$. Both families are of French Canadian origin and share the same haplotype except at D13S1831, D13S1832 and D13S143 indicating the presence of a historical recombinant at D13S1831. No double recombinants were identified.

\section{Allelic association and haplotype analysis}

We analysed 20 apparently unrelated French Canadian families for allelic association between HED and 10 markers in the candidate region. The results are shown in Table2. Significant evidence for linkage disequilibrium (LD) was found at all markers studied $(P<0.001)$. The strongest allelic association was detected between HED and alleles at markers D13S1828, D13S1827, D13S1835, D13S141 and D13S175. These markers had a $P_{\text {excess }}$ value of 1 indicating the presence of the associated alleles in $100 \%$ of affected chromosomes. While alleles 4 at D13S1827 and 2 at D13S141 are the most common alleles on the normal chromosomes $(67 \%$ and $57 \%$ respectively), alleles 9 at D13S1828 and 2 at D13S175 are less common ( $16 \%$ and $18 \%$, respectively). Allele2 at D13S1835 is not present on any control chromosome presenting an almost complete disequilibrium. The allelic excess drops to 0.68 with the most telomeric marker D13S143.

The significant allelic association between HED and the markers analysed strongly supports the founder effect 

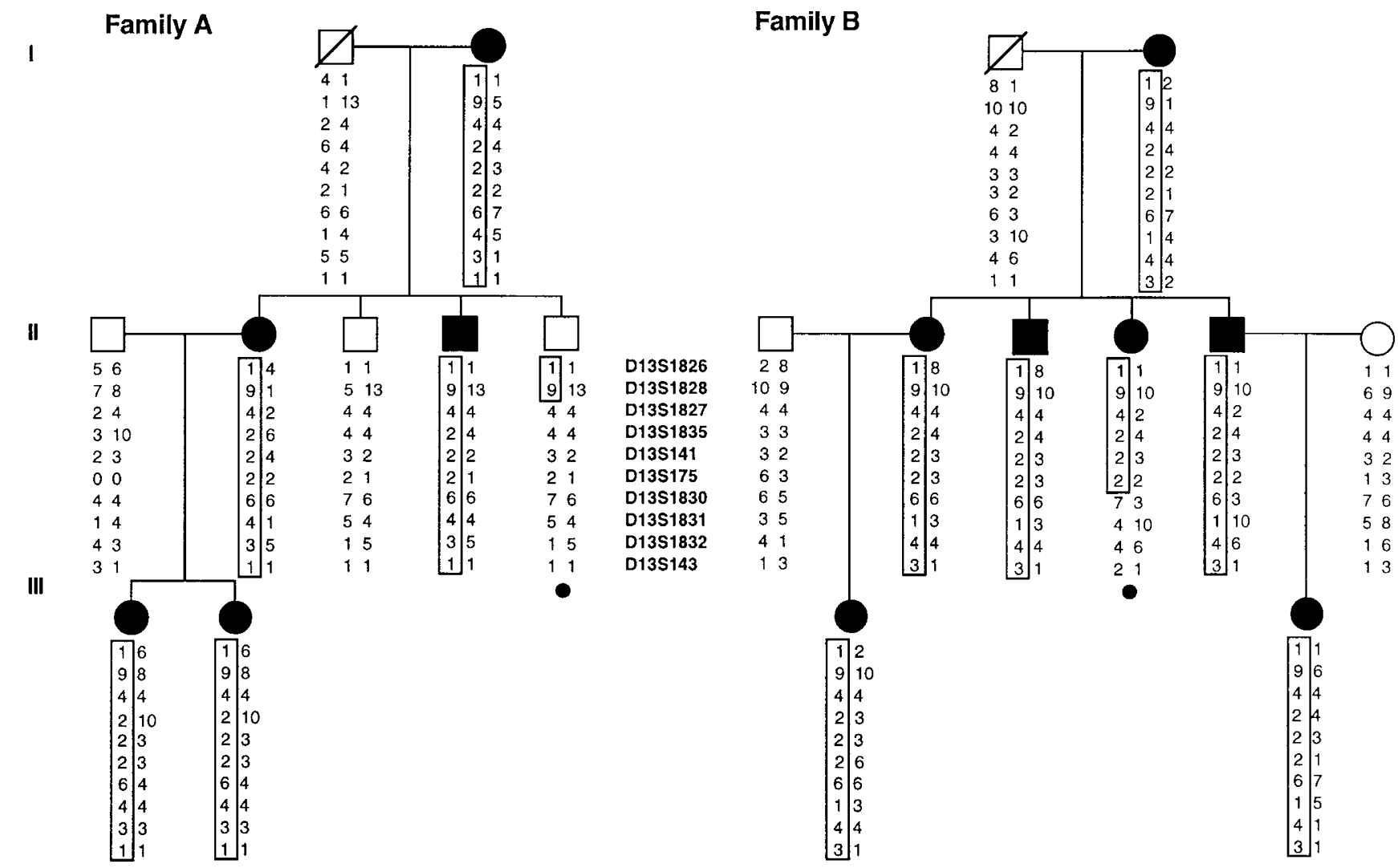

Figure 2 Pedigrees of two HED families showing two recombinants $(\bullet)$ that would place the HED gene telomeric to D13S1828 and centromeric to D13S1830. Phasing of haplotypes was deduced from available genotypes. The affected haplotypes are boxed. The order of markers used was obtained from an RH map constructed in the region ${ }^{11}$ and analysed with CRI-M AP using combined data from 14 CEPH families and $20 \mathrm{HED}$ families.

Table 2 Allelic association between HED and chromosome 13q markers

\begin{tabular}{|c|c|c|c|c|c|}
\hline \multirow[b]{2}{*}{ Marker } & \multirow{2}{*}{$\begin{array}{l}\text { Disease-associated } \\
\text { allele (size in bp) }\end{array}$} & \multicolumn{2}{|c|}{ Allele frequency ${ }^{a}$} & \multirow[b]{2}{*}{$\mathrm{P}^{\mathrm{b}}$} & \multirow[b]{2}{*}{$P_{\text {excess }}{ }^{\mathrm{c}}$} \\
\hline & & Affected & Normal & & \\
\hline D13S1826 & $1(112)$ & 0.92 & 0.33 & $1.9 \times 10^{-7}$ & 0.885 \\
\hline D13S1828 & 9 (127) & 1.00 & 0.16 & $<10^{-9}$ & 1.000 \\
\hline D13S1827 & 4 (189) & 1.00 & 0.67 & $2.9 \times 10^{-4}$ & 1.000 \\
\hline D13S1835 & 2 (129) & 1.00 & 0.00 & $<10^{-9}$ & 1.000 \\
\hline D13S141 & $2(124)$ & 1.00 & 0.57 & $1.1 \times 10^{-5}$ & 1.000 \\
\hline D13S175 & $2(104)$ & 1.00 & 0.18 & $<10^{-9}$ & 1.000 \\
\hline D13S1830 & $6(158)$ & 0.96 & 0.50 & $1.5 \times 10^{-5}$ & 0.924 \\
\hline D13S1831 & $1(91)$ & 0.85 & 0.14 & $<10^{-9}$ & 0.820 \\
\hline D13S1832 & $4(163)$ & 0.96 & 0.48 & $1.4 \times 10^{-5}$ & 0.923 \\
\hline D13S143 & 3 (128) & 0.73 & 0.15 & $2.4 \times 10^{-6}$ & 0.682 \\
\hline
\end{tabular}

aThe number of chromosomes studied was 26 affected and 56-58 normal; ${ }^{\mathrm{b}}$ The $\mathrm{P}$ value was generated using Fisher's exact test on a $2 \times 2$ table; ${ }^{c} P_{\text {excess }}=\left(P_{\text {affected }}-P_{\text {normal }}\right) /\left(1-P_{\text {normal }}\right)$.

hypothesis for the HED mutation in the French Canadian population. We consequently examined the affected chromosomes for the presence of an ancestral haplotype that most likely carried the founding mutation and of historical recombinants that would help us map the HED gene. The hapl otypes present on the affected French Canadian chromo- somes are shown in Table3. One major ancestral haplotype 1-9-4-2-2-2-6-1-4-3 was present on 17/26 (65\%) of the affected chromosomes. This ancestral haplotype most likely carries the conserved HED mutation. In addition, six minor haplotypes that most likely represent historical recombinants were detected. These recombinants define a core 
Table 3 HED-affected haplotypes in 20 French Canadian families. The common haplotype is shaded

\begin{tabular}{|c|c|c|c|c|c|c|c|c|c|c|}
\hline \multirow{2}{*}{$\begin{array}{l}\text { No of affected } \\
\text { chromosomes }\end{array}$} & \multicolumn{10}{|c|}{ Markers } \\
\hline & S1826 & S1828 & S1827 & S1835 & S141 & S175 & $\mathrm{S} 1830$ & S1831 & S1832 & S143 \\
\hline 17 & 1 & 9 & 4 & 2 & 2 & 2 & 6 & 1 & 4 & 3 \\
\hline 1 & 11 & 9 & 4 & 2 & 2 & 2 & 6 & 1 & 4 & 3 \\
\hline 1 & 9 & 9 & 4 & 2 & 2 & 2 & 6 & 1 & 4 & 3 \\
\hline 3 & 1 & 9 & 4 & 2 & 2 & 2 & 6 & 1 & 4 & 1 \\
\hline 2 & 1 & 9 & 4 & 2 & 2 & 2 & 6 & 10 & 4 & 1 \\
\hline 1 & 1 & 9 & 4 & 2 & 2 & 2 & 6 & 4 & 3 & $\overline{1}$ \\
\hline 1 & 1 & 9 & 4 & 2 & 2 & 2 & 7 & 4 & 4 & 2 \\
\hline
\end{tabular}

haplotype 9-4-2-2-2 at markers D13S1828, D13S1827, D13S1835, D13S175 and D13S141 that was shared by all affected chromosomes and was present on none of the control chromosomes. This core haplotype defines a 1.3-2.6 cM region that most likely harbours the HED gene.

\section{Luria-Delbrück analysis}

To further refine the position of the HED gene by LD analysis, the Luria and Delbrück derived equations ${ }^{20}$ were applied in this study. Because this method only tests one locus at a time, we determined an overlap of the likely range estimates calculated for all markers. The smal lest region of overlap was defined by the likely range of marker D13S1828, positioning the gene at marker $(\theta=0)$ with the likely range extending over $1.75 \mathrm{cM}, 0.03 \mathrm{cM}$ centromeric to $\mathrm{D} 13 \mathrm{~S} 1828$ and $0.70 \mathrm{cM}$ centromeric to D13S1830 (data not shown).

\section{Multipoint linkage disequilibrium analysis}

We next carried out multipoint linkage disequilibrium analysis using the likelihood method developed by JD Terwilliger. ${ }^{21}$ Results of this analysis are depicted in Figure 3. The maximum likelihood estimate was found to be 398.84 located $0.08 \mathrm{cM}$ telomeric to D13S1835 and $0.72 \mathrm{cM}$ centromeric to D13S141. The calculated 13.8 unit support interval (based on 1000:1 odds) spans an interval of $3.27 \mathrm{cM}$, $1.11 \mathrm{cM}$ centromeric to $\mathrm{D} 13 \mathrm{~S} 1826$ and $0.45 \mathrm{cM}$ centromeric to D13S1830. The heterogeneity parameter $\alpha$ of the DISMULT routine was 1 for the observed maximum likelihood, and the decay parameter 6 .

\section{Discussion}

Genetic homogeneity in HED was previously demonstrated in families of French Canadian, Indian and Scottish-Irish descent. ${ }^{5,6,9}$ Our results extend this finding to include families of African, Spanish, French and Malaysian origins. The African family was diagnosed as having a new form of ectodermal dysplasia different from HED, based mainly on the associated abnormal cardiac findings and absence of palmoplantar keratoderma in the affected members. ${ }^{13}$ However, our two-point analysis in this family suggests its linkage to the HED candidate region with a maximum lod score of 2.11 at zero recombination from D13S1826 and D13S1835. Consequently, we postulate that this family segregates either a new allele of the HED gene or one mutated gene responsible for this form of ectodermal dysplasia and closely linked to the HED gene or the HED gene with other defective gene responsible for the cardiac findings. As shown in Table4, a comparison of the affected chromosomes in the 29 families revealed seven different haplotypes. The French Canadian and Malaysian families share the same haplotype (2-2-2-6) between D13S1835 and D13S1830. To our knowledge, these families appear to be unrelated. These kindreds most likely carry distinct mutations of the HED gene, suggesting the presence of numerous ancestral mutations.

In this study, we used genetic analysis of 29 HED families with 10 polymorphic markers to narrow down the candidate interval. Recombination mapping placed the HED gene in a $2.4 \mathrm{CM}$ region flanked by $\mathrm{D} 13 \mathrm{~S} 1828$ at the centromeric side and D13S1830 at the tel omeric one. This region contains four cloned genes: connexin 26 (Cx 26), connexin 46 (Cx46), ${ }^{22}$ $\alpha$-tubulin TUBA $2^{23}$ and zinc finger ZNF198. ${ }^{24} \mathrm{C} \times 26$ was shown to be abundantly expressed in hair follicles ${ }^{25}$ and hence was considered as a good candidate for involvement in HED. However, no pathogenic mutation specific to HED was found in the coding sequence of this gene by PCR-SSCP analysis by our group (data not shown) and by sequencing. ${ }^{26}$ Later studies have described the presence of pathogenic mutations in Cx26 in hereditary non-syndromic sensorineural deafness. ${ }^{26} \mathrm{C} \times 46$ is highly expressed in the eye lens and found to be essential to its normal development. ${ }^{27}$ Pathogenic mutations in Cx46 have been reported in patients with autosomal dominant congenital cataract making it unlikely for this gene to be involved in HED. ${ }^{28}$ TUBA2 is an $\alpha$-tubulin whose expression appears to be testis-specific and hence is considered as a poor candidate for HED. ${ }^{23}$ ZNF198 is a novel gene with structural motifs believed to be involved in mediating homo- and heterotypic protein-protein interactions. $^{24}$ We are currently studying the possible involvement of this gene in HED.

The high frequency of HED in the French Canadian population suggests the presence of a founder effect and our linkage disequilibrium analysis in this study strongly supports this hypothesis. Given the particular population history, these findings are expected; however, the founder effect in HED is particularly interesting because of its unique origin and pattern of dissemination compared with other founder diseases studied in this population. The French Canadian population of Quebec was founded by $8000-10000$ colonists who came mostly from the central and western provinces of France during the period 1608-1759. These early settlers 


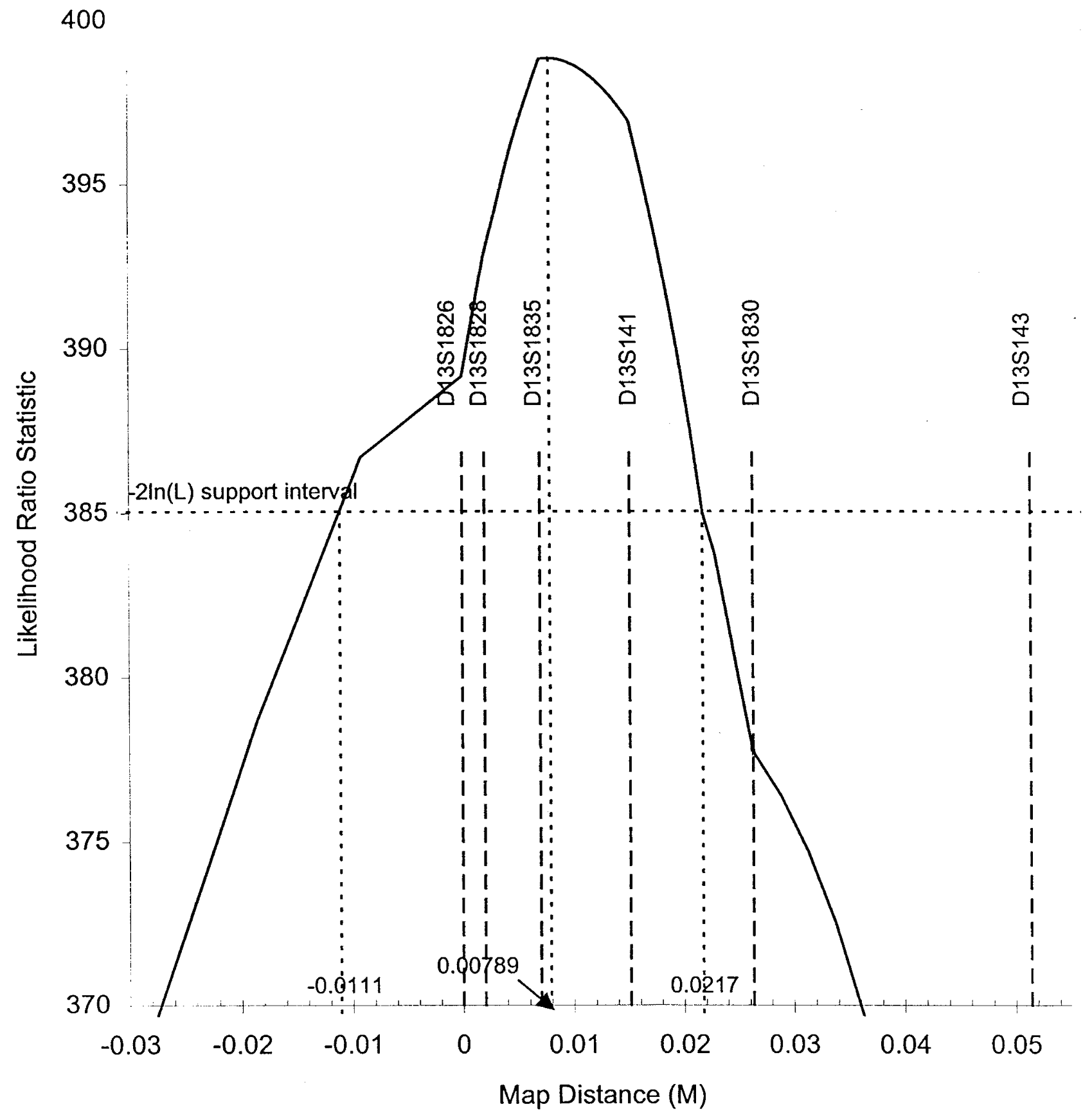

Figure 3 Multipoint linkage disequilibrium analysis of 20 French Canadian families using the DISMULT version 2.1 of the likelihood method developed by JD Terwilliger. ${ }^{21}$ The genetic map used: D13S1826-0.2 - D13S1828-0.5 - D13S1827-0.01 - D13S1835-0.8 D13S141-0.01 - -D13S175-1.1 - D13S1830-0.01 - D13S1831-0.01 - D13S1832-2.5 - D13S143.

established themselves mainly along St Lawrence River and gradually spread towards the Bas-St-Laurent region, Gaspésie and Charlevoix. By the mid-nineteenth century, an increase in population size stimulated migration to more remote regions of Québec such as the Saguenay region and to the United States. ${ }^{29}$ To date, most French Canadian genetic diseases described with a strong founder effect are partic- ularly common to the Charlevoix-Saguenay region in northeast Québec and are believed to originate around 12 generations in the past. ${ }^{30}$ On the other hand, HED is most frequent in the south-west part of the province and is believed to have been introduced later into the French Canadian population (eight or nine generations ago). Clouston who first studied the hereditary nature of HED in a large French Canadian 
Table 4 HED-affected haplotypes of seven different origins

\begin{tabular}{|c|c|c|c|c|c|c|c|c|c|c|}
\hline \multirow[b]{2}{*}{ Family origin } & \multicolumn{10}{|c|}{ Markers (allele size in bp) } \\
\hline & S1826 & S1828 & S1827 & S1835 & $\mathrm{S} 141$ & S175 & $\mathrm{S} 1830$ & S1831 & S1832 & S143 \\
\hline Indian & $4(118)$ & $6(121)$ & $3(187)$ & $\mathrm{ND}^{\mathrm{a}}$ & $2(124)$ & $3(106)$ & $3(152)$ & $2(95)$ & $6(167)$ & $1(124)$ \\
\hline Scottish-Irish & 9 (128) & 5 (119) & 4 (189) & $11(161)$ & $2(124)$ & $5(110)$ & $3(152)$ & $5(101)$ & $11(151)$ & 1 (124) \\
\hline French & 9 (128) & 5 (119) & $5(191)$ & 12 (169) & $3(126)$ & $3(106)$ & $7(160)$ & $5(101)$ & 4 (163) & 2 (126) \\
\hline French Canadian & $1(112)$ & 9 (127) & $4(189)$ & 2 (129) & $2(124)$ & $2(104)$ & $6(158)$ & $1(91)$ & $4(163)$ & $3(128)$ \\
\hline Spanish & $7(124)$ & 10 (129) & $4(189)$ & 10 (159) & $1(114)$ & $3(106)$ & $6(158)$ & 9 (109) & $3(161)$ & 1 (124) \\
\hline African & $2(114)$ & 5 (119) & 4 (189) & 5 (135) & $2(124)$ & 3 (106) & 6 (158) & $3(97)$ & 8 (171) & 1 (124) \\
\hline Malaysian & 6 (122) & 6 (121) & 5 (191) & 2 (129) & $2(124)$ & 2 (104) & 6 (158) & 6 (103) & 2 (159) & 1 (124) \\
\hline
\end{tabular}

ano data.

Multipoint Terwilliger

Luria-Delbruck

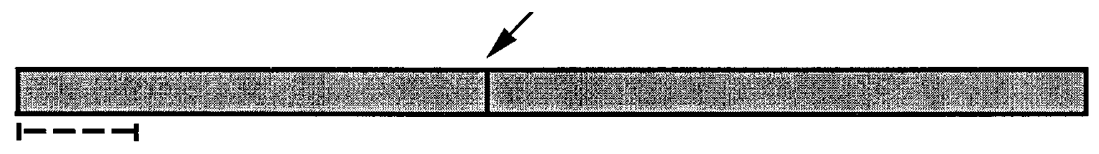

$1.11 \mathrm{cM}$

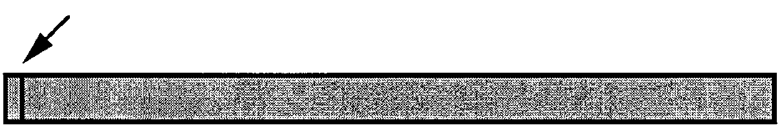

Mulipoint linkage

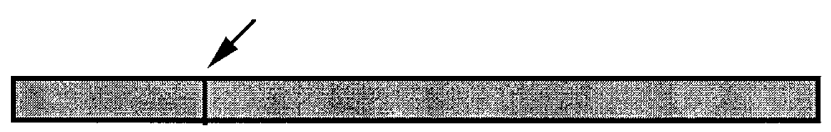

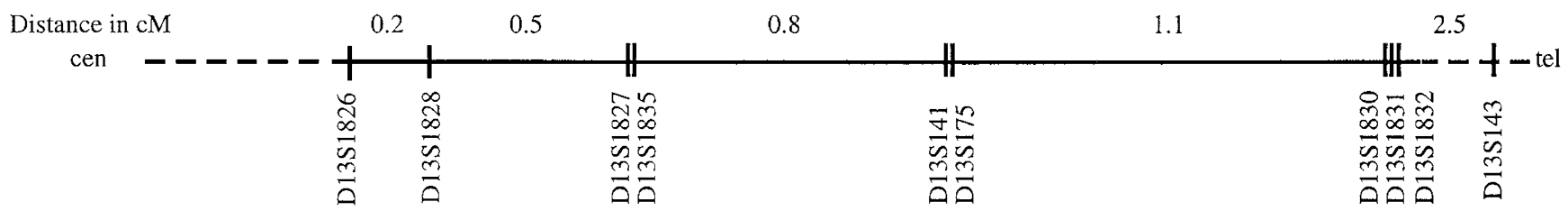

Figure 4 Summary of the results obtained with multipoint linkage and linkage disequilibrium analyses. Arrows and shaded boxes respectively indicate the most likely positions of the HED gene and support intervals obtained with these analyses.

family living in Huntingdon in the south-west part of Québec described the remarkably high frequency of this disease in this part of the province. ${ }^{7,8}$ In fact, most of our families originate from that region; the disease is rare in north-east Québec. Clouston inferred that the mutation was introduced into the French Canadian population by a French individual some time before the battle of the Plains of Abraham in 1759. This assumption is not supported by our haplotype analysis of a French family originating from Lorraine in the eastern part of France. The affected haplotype in this family is different from that in the French Canadian families and hence it most likely carries a historically distinct mutation. Reconstructed ancestral genealogies of HED patients should provide additional information on the founding of this disease in the French Canadian population.

The presence of a founder effect for HED in the French Canadian population makes linkage disequilibrium (LD) mapping a possible tool to refine the localisation of the HED gene. Despite the recent founding of this population, its rapid growth and relative isolation have made it well suited for LD fine mapping. ${ }^{19,31}$ We applied two different LD mapping methods in our study to finely map the HED gene: the Luria-Delbrück equation and a multipoint likelihood method developed by JD Terwilliger. The Luria-Delbrück equation placed the HED gene at the D13S1828 locus while the other method estimated its most likely position at $0.58 \mathrm{cM}$ telomeric to this marker. Confidence intervals obtained in both analyses are large, extending over $1.75 \mathrm{cM}$ and $3.25 \mathrm{cM}$, respectively; however Luria-Delbrück equation provided a finer estimate for the map position of the HED gene relative to the candidate interval defined by recombination mapping (D13S1828-D13S1830). Because of the errorprone assumptions associated with the LD mapping methods, these results are best used in guiding our strategies in subsequent steps of positionally cloning the HED gene.

Recombination mapping in this study places the HED gene in a $2.4 \mathrm{cM}$ region which is still large for positional cloning efforts. Figure 4 summarises the results obtained with linkage and linkage disequilibrium analyses. As shown in this figure, 
the HED gene resides most likely in the centromeric part of this region. These results will guide our strategies for physical mapping and cloning of the HED gene and we will aim at constructing a physical map around D13S1828, D13S1827, D13S1835, D13S141 and D13S175. Finer mapping of the HED gene by genetic analysis requires the collection of additional families and isolation of new polymorphic markers from the candidate region. However, it will be difficult to find more recombinants in this region because of its pericentromeric localisation.

\section{Acknowledgements}

We would like to thank the families that made this study possible. This work was supported by grants from the Canadian Dermatology Foundation (GAR), the National Foundation for Ectodermal Dysplasias (GAR and JZ) and NIDR DE11311 (JZ). GAR is supported by the Medical Research Council of Canada.

\section{References}

1 Williams M, Fraser FC: Hydrotic ectodermal dysplasia-Clouston's family revisited. Can Med Ass J 1967; 96: 36-38.

2 Mcnaughton PZ, Pierson L: Hidrotic ectodermal dysplasia in a black mother and daughter. Arch Dermatol 1976; 112: 1448-1450

3 Rajagopalan K, Hai Tai C: Hidrotic ectodermal dysplasia. Arch Dermatol 1977; 113: 481-485.

4 Ando $\mathrm{Y}$, Tanaka T, Horiguchi Y, Ikai K, Tomono H: Hidrotic ectodermal dysplasia. Dermatologica 1988; 176: 205-211.

5 Radhakrishma U, Blouin J-L, Mehenni $H$ et al: The gene for autosomal dominant hidrotic ectodermal dysplasia (Clouston syndrome) in a large Indian family maps to the 13q11-q12.1 pericentromeric region. Am J Med Genet 1997; 71: 80-86.

6 Taylor TD, Hayflick SJ, McKinnon W et al: Confirmation of linkage of Clouston syndrome (hidrotic ectodermal dysplasia) to 13q11-q12.1 with evidence for multiple independent mutations. J Invest Dermatol 1998; 111: 83-85.

7 Clouston HR: Hereditary ectodermal dystrophy. Can Med Ass J 1929; 21: 18-31.

8 Clouston HR: The major forms of hereditary ectodermal dysplasia. Can Med Ass J 1939; 40: 1-7.

9 Kibar Z, Der Kaloustian VM, Brais B, Hani V, Fraser FC, Rouleau GA: The gene responsible for Clouston hidrotic ectodermal dysplasia maps to the pericentromeric region of chromosome13q. Hum Mol Genet 1996; 5: 543-547.

10 Der Kaloustian VM, Kurban AK: Hyperplasias, aplasias, and atrophies. In: Der Kaloustian VM, Kurban AK (eds). Genetic Diseases of the Skin. Springer-Verlag: 1979, pp 90-139.

11 Kibar Z, Lafrenière RG, Chakravarti $A$ et al: A radiation hybrid map of 48 loci including the Clouston hidrotic ectodermal dysplasia (HED) locus in the pericentromeric region of chromosome13q. Genomics 1999; 56: 127-130.

12 Hayflick S), Taylor T, McKinnon W, Guttmacher AE, Litt M, Zonana J: Clouston syndrome (hidrotic ectodermal dysplasia) is not linked to keratin gene clusters on chromosomes 12 and 17. J Invest Dermatol 1996; 107: 11-14.

13 Christianson AL, Fourie S: Family with autosomal dominant hidrotic ectodermal dysplasia: a previously unrecognized syndrome? Am J Med Genet 1996; 63: 549-553.
14 Giraud F, Mattei JF, Rolland M, Ghiglione C, Pommier de Santi P, Sudan N: La dysplasie ectodermique de type Clouston. Arch Franç Péd 1977; 34: 982-993.

15 Stevens HP, Choon SE, Hennies H-C, Kelsell DP: Evidence for a single genetic locus in Clouston's hidrotic ectodermal dysplasia. Br J Dermatol 1999; 140: 963-964.

16 Lander E, Green P: Construction of multilocus genetic linkage maps in humans. Proc Natl Acad Sci USA 1987; 84: 2363-2367.

17 Terwilliger JD, Ott J: Running the LINKAGE programs MLINK and ILINK. In: Terwilliger JD, Ott J (eds). Handbook of Human Genetic Linkage. Johns Hopkins University Press: London, 1994, pp 22-32.

18 O'Connell JR, Weeks DE: The VITESSE algorithm for rapid exact multilocus linkage analysis via genotype set-recoding and fuzzy inheritance. Nat Genet 1995; 11: 402-408.

19 Casaubon LK, Melanson M, Lopes-Cendes I et al: The gene responsible for a severe form of peripheral neuropathy and agenesis of the corpus callosum maps to chromosome15q. Am J Hum Genet 1996; 58: 28-34.

20 Hästbacka J, de la Chappelle A, Kaitila I, Sistonen P, Weaver A, Lander E: Linkage disequilibrium mapping in isolated founder populations: diastrophic dysplasia in Finland. Nat Genet 1992; 2: 204-211.

21 Terwilliger JD: A powerful likelihood method for the analysis of linkage disequilibrium between trait loci and one or more polymorphic marker loci. Am J Hum Genet 1995; 56: 777-787.

22 Mignon C, Fromaget C, Mattei MG, Gros D, Yamasaki H, Mesnil M: Assignment of connexin 26 (GJB2) and 46 (GJA3) genes to human chromosome13q11-q12 and mouse chromosome 14D1-E1 by in situ hybridization. Cytogenet Cell Genet 1996; 72: 185-186.

23 Guilford P, Dode C, Crozet F et al: A YAC contig and an EST map in the pericentromeric region of chromosome 13 surrounding the loci for neurosensory nonsyndromic deafness (DFNB1 and DFNA3) and limb-girdle muscular dystrophy type 2C (LGMD2C). Genomics 1995; 29: 163-169.

24 Reiter A, Sohal J, Kulkarni S et al: Consistent fusion of ZNF198 to the fibroblast growth factor receptor- 1 in the $t(8 ; 13)(p 11 ; q 12)$ myeloproliferative syndrome. Blood 1998; 92: 1735-1742.

25 Salomon D, Masgrau E, Vischer Set al: Topography of mammalian connexins in human skin. J Invest Dermatol 1994; 103: 240-247.

26 Kelsell DP, Dunlop J, Stevens HP: Connexin 26 mutations in hereditary non-syndromic sensorineural deafness. Nature 1997; 387: 80-83.

27 Paul DL, Ebihara L, Takemoto LJ, Swenson KI, Goodenough DA: Connexin 46, a novel lens gap junction protein, induces voltagegated currents in nonjunctional plasma membrane of Xenopus oocytes. J Cell Biol 1991; 115: 1077-1089.

28 Mackay D, lonides A, Kibar Z et al: Connexin 46 mutations in autosomal dominant congenital cataract. Am J Hum Genet 1999; 64: 1357-1364.

29 Heyer E: Mitochondrial and nuclear genetic contribution of female founders to a contemporary population in Northeast Québec. Am J Hum Genet 1995; 56: 1450-1455.

30 Bouchard G, De Braekeleer M: Mouvements migratoires, effets fondateurs et homogénéisation génétique; in Histoire D'un Génome. Presses de I'Université de Québec: Québec, 1991, pp 283-321.

31 Labuda M, Labuda D, Korab-Laskowska $M$ et al: Linkage disequilibrium analysis in young populations: Pseudo-vitamin D-deficiency rickets and the founder effect in French Canadians. Am J Hum Genet 1996; 59: 633-643. 